\title{
The Research on Some Thermo-sensitive Parameters of IGBT's Junction Temperature
}

\author{
Jiachen Tian \\ School of Electrial Engineering, Xi'an Jiaotong University, Xi'an 710049, China. \\ tianjiachen1995@stu.xjtu.edu.cn
}

Keywords: IGBT; conduction voltage drop; oscillating voltage; junction temperature.

Abstract: Due to IGBT (Insulated Gate Bipolar Transistor)'s excellent ability to process electric power, it is widely used in power transformation at present, however, destructions of IGBT have reached by 60 percent due to the rise of IGBT's junction temperature. On the one hand, this paper proposes the defect of difference between conduction voltage drop at different driver voltages as a thermal parameter from the angle of static thermal parameter method, and proposes a circuit which uses operational amplifier to achieve voltage reduction while accurately measures the conduction voltage drop; On the other hand, from the angle of dynamic thermal parameter method, this paper uses the amplitude of oscillating voltage generated by the inductor to reflect the change in junction temperature dynamically.

\section{Introduction}

Power electronic devices are widely used in power conversion and power control due to their good withstand voltage and current resistance, however, because electric power of device is too large, junction temperature of device is likely to rise, which may affect the operation of the device and cause damage to the structure of the device. At present, more than $60 \%$ of the device damages are caused by an increase in junction temperature of device, therefore, improvements on assessment methods of IGBT's junction temperature are of great significance for maintaining the quality of power conversion and the efficiency of power control, and are also of great significance for protecting the structure and normal functions of IGBT.

There are many methods to improve the junction temperature monitoring control and reduce the junction temperature damage rate, including physical contact method, thermal model construction method and thermal parameter method, the physical contact method has low measurement accuracy and the thermal model construction method is complicated, the feasibility in actual production is not high, and the thermal parameter measurement method is often used, the thermal parameter analysis method is divided into static parameter measurement method and dynamic parameter measurement method, this text improves the existing circuit by analyzing the static parameter measuring circuit proposed in existing literature. On the one hand, this text designs a diode voltage clamp circuit, when the IGBT is turned off, the higher turn-off voltage at both ends of IGBT is reduced to zero by the operating amplifier, and the diodes of voltage clamping circuit are not broken down, when conducting, this circuit directly measures the specific value of the conduction voltage drop with a 
voltmeter to improve accuracy of measurement; On the other hand, this text analyzes the conduction process of IGBT, measuring the inductance (L,see in Figure 6) in parallel at the collector, and replacing the IGBT saturation current with the current source $\mathrm{I}_{c}$, because the IGBT's junction temperature has a positive correlation with the saturation current, and the oscillating voltage of the inductance (L) is measured, magnitude of amplitude has a negative correlation with the saturation current, so the smaller the amplitude of oscillating voltage, the higher the IGBT's junction temperature.

\section{Static Thermal Parameter Method}

The conduction voltage drop is an important thermal parameter of IGBT, which is the main reason for IGBT's heating, it is often used to reflect the junction temperature change of IGBT, many literatures have proposed circuits for measuring the conduction voltage drop, or indirectly uses the conduction voltage drop as a thermal parameter.

An article in Reference 3 proposes a difference between different conduction voltage drop of the IGBT under different driver voltages $V_{\text {ge }}$ as a new thermal parameter to ensure that the collector current $i_{c}$ and the junction temperature ( $T$, see in FIGURE 1) remain unchanged during the conduction process, and at the same time only changes the drivier voltage $V_{\text {ge }}$ between the gate and emitter of IGBT, it can be seen from the simulation software that magnitude of drivier voltage affects the conduction voltage drop so that a certain difference $\Delta \mathrm{V}_{\text {ce }}$ will be generated.

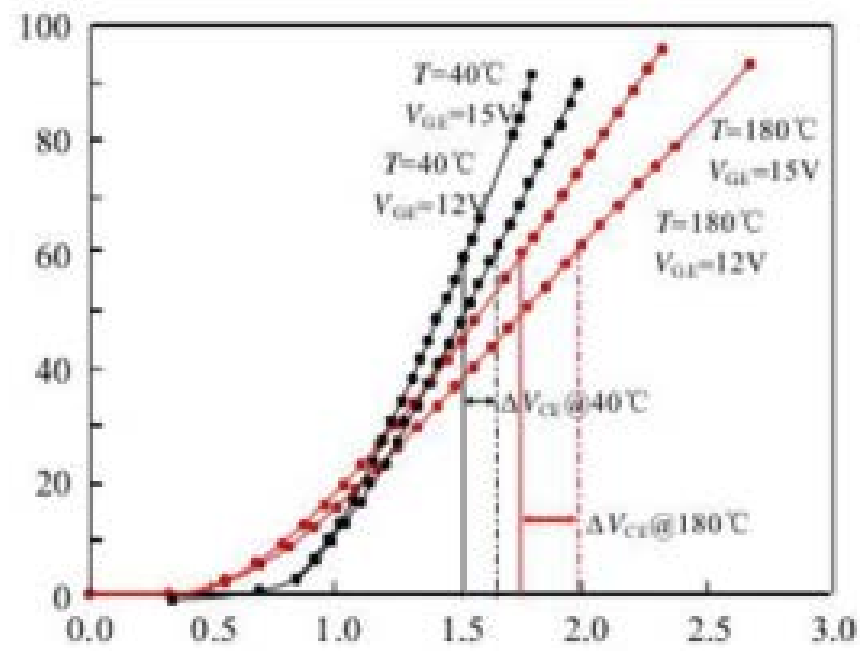

Figure 1. Steady performance of device under test with different driver voltage.

The rest of the literature also proves that $\Delta \mathrm{V}_{\text {ce }}$ has a positive correlation with the junction temperature $(T)$ in all range of collector current $i_{c}$, and has good linearity, however, there are many problems in this scheme, including the poor operability and the high measurement errors, the driving voltage applied by the gate will affect the conduction voltage drop value of IGBT, and the conduction voltage drop is the main factor affecting the junction temperature of IGBT, the method for measuring the voltage is to change the value of the driving voltage $\mathrm{V}_{\text {ge }}$ under the condition that the IGBT's junction temperature and the collector current ic are constant, and measure the value of conduction voltage drop $\mathrm{V}_{\text {ce }}$ respectively, and then make a difference., however, due to the change of driving voltage, the conduction voltage drop changes accordingly, which leads to different degrees of IGBT's heat generation during two measurement processes, it is very difficult to keep the junction temperature consistent.

If you want to measure the same junction temperature, you need to stagger the time of two 
measurements to ensure that the junction temperature keeps the same, the collector current $i_{c}$ can use a micro current source or a mirror phase current source to ensure a stable output, but the current has a self-heating effect, which will increase the on-resistance $\mathrm{R}_{\text {on }}$ and tube consumption, since the time of two measurements is different, the self-heating effect will affect the change of junction temperature, therefore, selection of conduction voltage drop measurement time is very difficult, and it is not easy to apply this method into practice.

Changing IGBT's driving voltage frequently increases instability of tube and may cause permanent damage to IGBT, the IGBT has a fine structure, and only one oxide film is isolated between the gate and the emitter, and the breakdown voltage is low, only 20-30V, the structure of IGBT's transistor is complicated, including the distributed capacitance $\mathrm{C}_{\mathrm{gc}}$ between the gate and the collector, the distributed capacitance $\mathrm{C}_{\mathrm{ge}}$ between the gate and the emitter, and the distributed inductance $\mathrm{L}_{\mathrm{e}}$ in the emitter driving circuit.

In IGBT's start-up process, it is divided into two stages: In the initial stage, the $\mathrm{C}_{\mathrm{ge}}$ and triode input resistance $R_{g}$ will affect driver voltage $V_{\text {ge }}$, when $V_{g e}>V_{\text {th }}$, IGBT starts to conduct, and the collector current $i_{c}$ starts to rise rapidly, at this time, there are two main factors affecting the rise of $\mathrm{V}_{\text {ge }}$. On the one hand, the emitter's distribution inductance $L_{b}$ will generate an induced electromotive force, which will hinder the rise of $\mathrm{V}_{\text {ge }}$; On the other hand, during the rapid rise of $\mathrm{V}_{\mathrm{ge}}, \mathrm{i}_{\mathrm{c}}$ will reach a peak at a certain moment and then decrease, at this time, $\mathrm{C}_{\mathrm{gc}}$ will discharge and affect $\mathrm{V}_{\text {ge }}$ 's rise[1].

When using this scheme to measure $\Delta \mathrm{V}_{\text {ce}}$, if multiple sets of measurement data are required, the value of drivier voltage $\mathrm{V}_{\text {ge }}$ needs to be changed frequently, but the frequent change of $\mathrm{V}_{\text {ge }}$ may cause the oscillating voltage of the damaged oxide layer and reduce the service life of IGBT.

Based on the above two points, this text considers that this scheme is only a theoretically superior solution, but there are too many shortcomings in practical applications, this scheme has low accuracy and low feasibility even if the linearity of this method is good.

Many literatures have proposed circuits for measuring the conduction voltage drop, but they all have certain defects, some circuits require high measurement environments, and some circuits have poor measurement accuracy. For example, this circuit introduced by Reference 2 puts a voltage which is bigger than the threshold voltage on the gate of the power transistors when a current flows through the freewheeling diode $\mathrm{D}_{1}$.

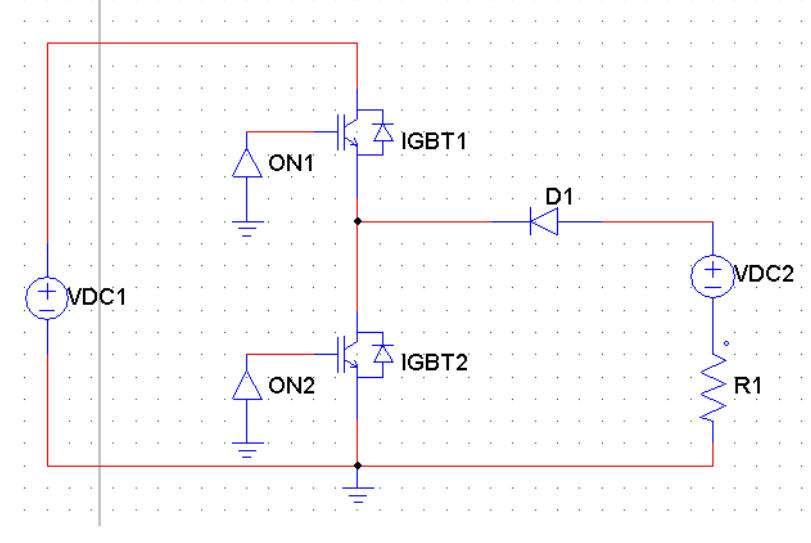

Figure 2. The circuit of measurement proposed by Reference 2.

However, this circuit demands high level of accuracy and it is difficult to keep $\mathrm{V}_{\text {ge }}$ into IGBT's saturation area, because IGBT's saturation area is narrow, if we want that IGBT's saturation area is in a state of saturation, the voltage between the collector and emitter should be maintained at a very low level, current can be measured under this accurate voltage. In general, IGBT's conduction pressure drop is between $1.8 \mathrm{~V}$ and $2.2 \mathrm{~V}$, the requests of accuracy of this circuit in Figure 1 are too 
high, through the careful design of circuit, this text introduces a new circuit to measure the conduction pressure drop of the IGBT to deal to solve the problem that $\mathrm{V}_{\text {ce }}$ is high when IGBT is shut-off and $\mathrm{V}_{\text {ce }}$ is low when IGBT is conducted, therefore, it is significant to improve the accuracy of measurement.

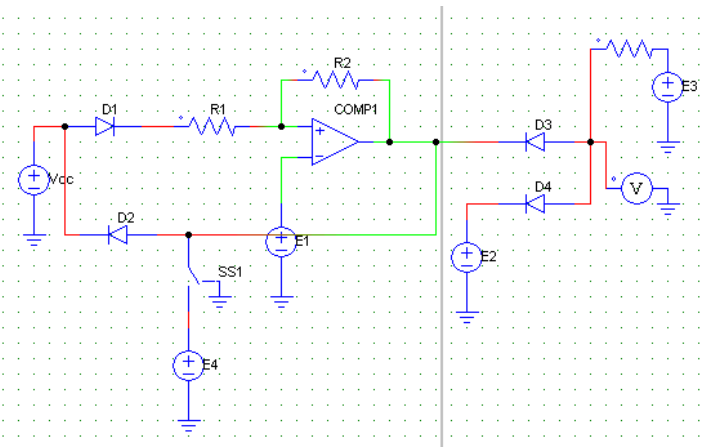

Figure 3. The diode clamp circuit improved

Table 1. Parameters of measuring circuit

\begin{tabular}{|c|c|c|}
\hline Nembers & Component name & Parameter value \\
\hline 10 & $\mathbf{R}_{\mathbf{r}}$ & $10 \Omega$ \\
\hline 20 & $\mathbf{R}_{3}=$ & $10 \mathrm{~kg}=$ \\
\hline 3. & $E_{2}=$ & $10 \mathrm{~V}=$ \\
\hline 4. & $E_{2}=$ & 10ve \\
\hline so & $\mathrm{v}_{e}$ & $10 \mathrm{~V}=$ \\
\hline$\infty$ & $R_{9=0}$ & $5 \Omega$ \\
\hline 70 & $E_{30}$ & $10 \mathrm{~V}$ \\
\hline s. & $E_{40}$ & svo \\
\hline 9 & $\mathrm{VDC}_{1}$ (in conduaction) = & $1.8 v=$ \\
\hline 100 & $\mathrm{VDC}=$ (sturdown) & $1000 \mathrm{~V}=$ \\
\hline
\end{tabular}

When the IGBT is shut-off, the voltage $\mathrm{V}_{\text {ce }}$ which is between the collector and the emitter is high, the circuit above can decrease the voltage to zero through the operational amplifier, when the IGBT is conducting, the switch $\mathrm{ss}_{1}$ is closed and the circuit can measure the voltage accurately through the voltmeter.

Due to the virtual short and the virtual open of the operational amplifier, this measuring circuit can deal with two different circuit status to avoid the complex circuit designs and improve the accuracy of the measurement.

The circuitous philosophy is as following:

$$
\begin{gathered}
\left(\mathrm{U}_{\mathrm{i}}-\mathrm{E}_{1}\right) / \mathrm{R}_{1}=\left(\mathrm{E}_{1}-\mathrm{U}_{\mathrm{o}}\right) / \mathrm{R}_{2} \\
\mathrm{U}_{0}=\left(1+\mathrm{R}_{2} / \mathrm{R}_{1}\right) \mathrm{E}_{1}-\left(\mathrm{R}_{2} / \mathrm{R}_{1}\right) \mathrm{E}_{1} \\
\mathrm{R}_{2}<<\mathrm{R}_{1}
\end{gathered}
$$

In the Mathematical expressions above:

$\mathrm{U}_{\mathrm{i}}$-The input voltage;

$\mathrm{U}_{0}$-The output voltage; 


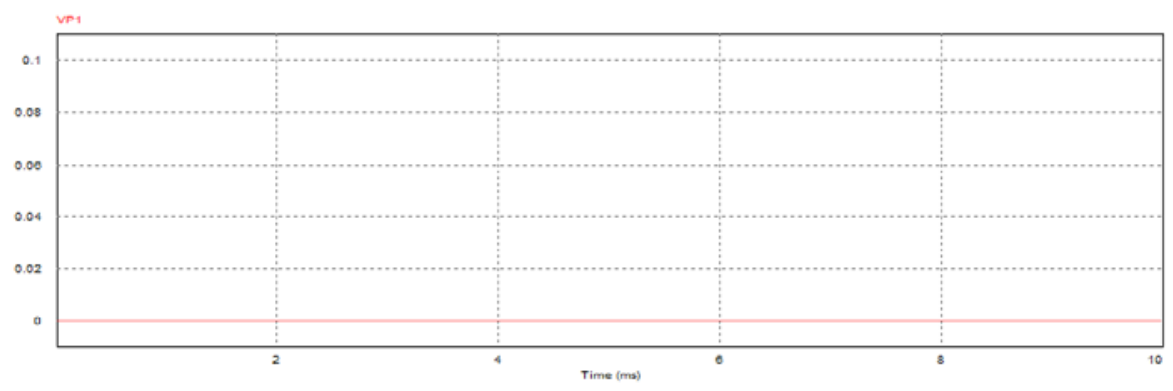

Figure 4. Measurement of $\mathrm{V}_{\text {ce }}$ when IGBT is shut-off

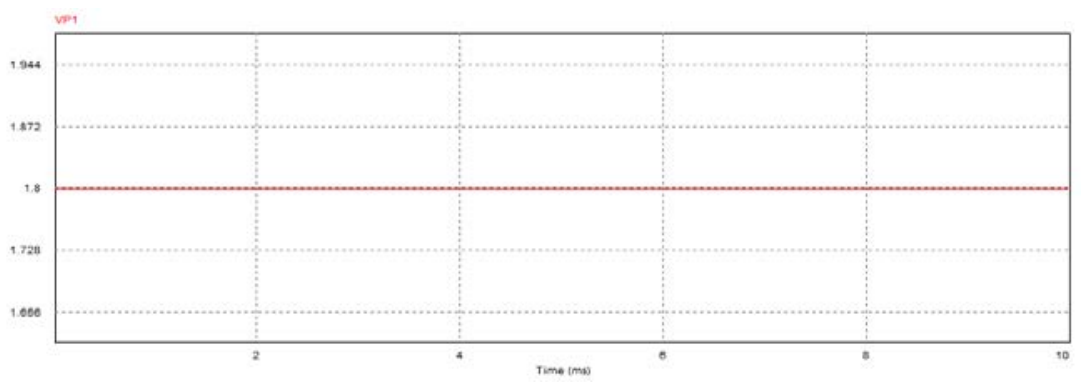

Figure 5. Measurement of conduction pressure drop

Through the improvements of the text, the circuit uses the basic equipments to decrease voltage and measures the $\mathrm{V}_{\mathrm{ce}}$ accurately, the diode voltage regular circuit can keep the voltage at a single level easier than zener diode [2].

\section{Dynamic Thermal Parameter Method}

This text proposes a method to reflect dynamic changes of IGBT's junction temperature and proves that this time slot $\Delta \mathrm{t}\left(\Delta \mathrm{t}=\mathrm{t}_{4}-\mathrm{t}_{3}\right)$ has a positive correlation with junction temperature, when IGBT begins to conduct, the miller capacitance $C_{g c}$ begins to charge and drive current $i_{g}$ begins to build, the result is that drive voltage $\mathrm{V}_{\text {ge }}$ rises sharply.

From the $t_{1}$ moment, $V_{c e}$ begins to surpass the threshold voltage $V_{t h}$, the miller capacitance $C_{g c}$ begins to charge and collector current $i_{c}$ increases sharply, the huge current rate of change has produced a huge induction electromotive force on parasitic inductance of emitter, collector current $\mathrm{i}_{\mathrm{C}}$ begins to build and $\mathrm{V}_{\mathrm{ce}}$ begins to decrease. $\mathrm{I}_{\mathrm{C}}$ increases to peak at $\mathrm{t}_{2}$ moment.

From the $t_{2}$ moment, the depletion layer of IGBT is continuously widened so that $\mathrm{C}_{\mathrm{gc}}$ begins to discharge and $i_{c}$ begins to decrease, after the $t_{3}$ moment, the collector current $i_{c}$ begins to keep constant, it is also proved that $\mathrm{C}_{\mathrm{gc}}$ and other parasitic inductances cannot affect the oscillating voltage produced by (L).

In order to improve accuracy of measurement, the text proposes a method which parallels an inductor (L) at collector, the induction electromotive force produced by (L) has a positive correlation with junction temperature, the $t_{4}$ moment is when induction electromotive force produced by (L) decreases to zero, this text measures the oscillating voltage produced by $(\mathrm{L})$, which its amplitude has a negative correlation with junction temperature, this dynamic parameter can demonstrate dynamic changes of junction temperature [3] 


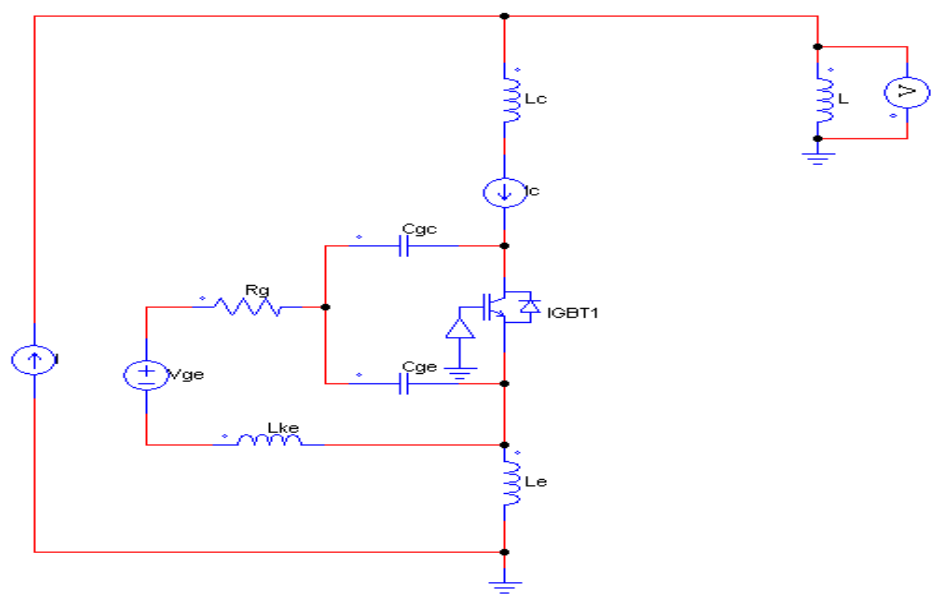

Figure 6. Test circuit

Table 2. Parameters of experiment

\begin{tabular}{|c|c|c|}
\hline Subes & Conpontar name & Parzaeter valus \\
\hline $1 *$ & L. & $0.1 \mathrm{H}$ \\
\hline 2 & $\mathrm{R}_{\mathrm{r}}$ & $27 \Omega$ \\
\hline 3 & I & $400 \mathrm{~A}=$ \\
\hline 4 & $\mathrm{I}_{*}$ & $100200300 / 350 A$ \\
\hline
\end{tabular}

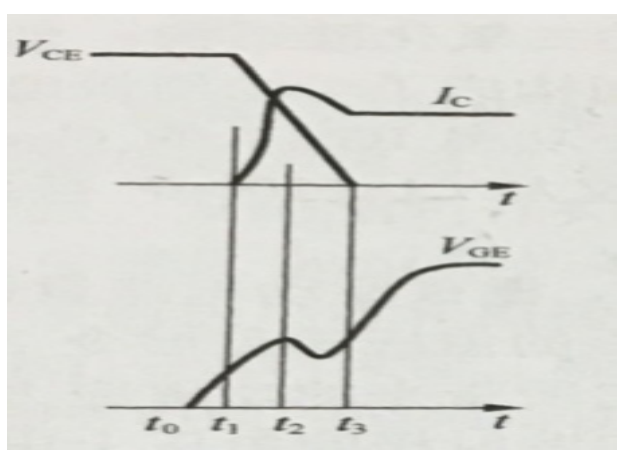

Figure 7. Conducting time of IGBT

In this text, the magnitude of the induced electromotive force generated by the inductor objectively reflects the junction temperature, the current source $I_{c}$ (see in FIGURE 6) represents the saturation current flowing through the IGBT, when the driving voltage $\mathrm{V}_{\text {ge }}$ is constant, collector current $i_{c}$ of IGBT and junction temperature $(\mathrm{T})$ are positively correlated, the higher junction temperature (T) of IGBT, the larger the collector current $i_{c}$, the smaller current flowing through the test inductor (L), and the lower the amplitude of the oscillating voltage generated in the inductor, therefore, junction temperature of IGBT has a negative correlation with amplitude of oscillating voltage [4].

The measuring circumstance is under the action of current source I (see in FIGURE 6) of 400A, the magnitude of current source $\left(\mathrm{I}_{\mathrm{C}}\right)$ is changed, and the wave form of oscillating voltage generated by inductor $(\mathrm{L})$ is tested under the condition that the on-current $\mathrm{i}_{\mathrm{C}}$ is $100 \mathrm{~A}, 200 \mathrm{~A}, 300 \mathrm{~A}$ and $350 \mathrm{~A}$ 
respectively, the wave form is shown as below:

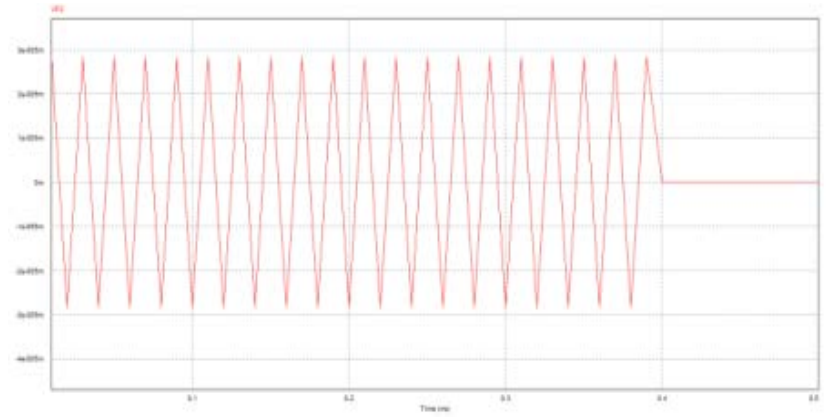

Figure 8. The oscillation wave form of $(\mathrm{L})$ when $\mathrm{i}_{\mathrm{c}}$ is $350 \mathrm{~A}$

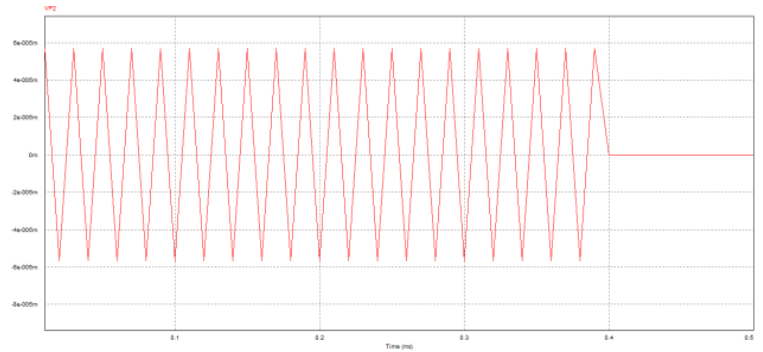

Figure 9. The oscillation wave form of $(\mathrm{L})$ when $\mathrm{i}_{\mathrm{c}}$ is $300 \mathrm{~A}$

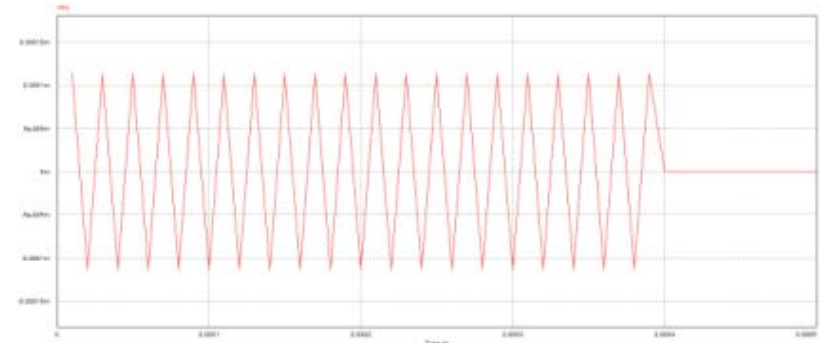

Figure 10. The oscillation wave form of $(L)$ when $i_{c}$ is $200 A$

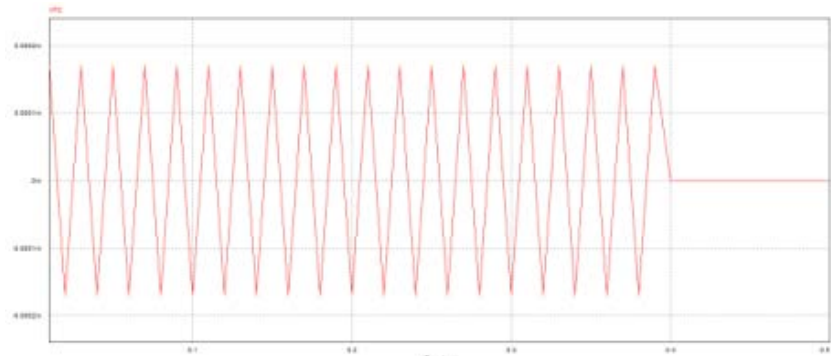

Figure 11. The oscillation wave form of $(L)$ when $i_{c}$ is $100 \mathrm{~A}$

\section{Conclusion}

If the difference between the on-voltage drops at different driving voltages is used as the thermal parameter, changing value of IGBT's driving voltage frequently may increase the instability of IGBT and destroy the structure of IGBT, therefore, this method is realistic in practice.

Concerned with the measuring circuit proposed in this text, when IGBT is turned off, the high voltage is reduced to zero by the operational amplifier circuit; When IGBT is turned on, the switch $\mathrm{SS}_{1}$ is combined so that the diode $\mathrm{D}_{2}$ is turned on, at the same time, the conduction voltage drop is 
accurately measured to reflect changes in junction temperature.

In this text, the IGBT's collector is connected in parallel with the inductor (L), and current source $I_{c}$ is used as the saturation current ic flowing through the IGBT, through changing the value of $\left(\mathrm{I}_{\mathrm{C}}\right)$, the amplitude of oscillating voltage of $(\mathrm{L})$ can reflect the change of junction temperature.

\section{References}

[1] Anis Ammous. Bruno Allard,Transient temperature measurement and modeling of IGBT's under short circuit, IEEE Transactions on Power Electronics, 1998, 13(1), pp.12-25.

[2] Wuhua Li, Yuxiang Chen, Zehao Luo, Principle and review of junction temperature extraction for large capacity power electronic devices ,Proceedings of the CSEE,2016,36(13):3546-3557.

[3] Pengfei Sun, Zehao Luo, Junction temperature extraction of high power IGBT module based on turn-off time, Proceedings of the CSEE, 2015, 35(13): 3366-3372.

[4] Pengfei Sun, Development and application of high power IGBT module switching performance test platform, 2015. 